\title{
Estimativas de parâmetros genéticos em genótipos de feijão-frade
}

\section{Estimates of genetic parameters in cowpea genotypes}

\author{
Everardes Públio Júnior1,*, Douglas G. Guimarães², Ana Paula P. B. Públio², Ubiratan 0. Souza³ \\ e Cláudio Lúcio F. Amaral4
}

\author{
${ }^{1}$ Instituto Federal de Educação, Ciência e Tecnologia da Bahia, Campus Eunápolis, Bahia, Brasil \\ 2 Universidade Estadual do Sudoeste da Bahia, Programa de Pós-Graduação em Agronomia, Campus de Vitória da Conquista, Vitória da Conquista, Bahia, Brasil \\ ${ }^{3}$ Instituto Federal de Educação, Ciência e Tecnologia Baiano, Campus Bom Jesus da Lapa, Bom Jesus da Lapa, Bahia, Brasil \\ 4 Universidade Estadual do Sudoeste da Bahia (DCB/LABGENEX), Programa de Pós-Graduação em Agronomia, Campus de Vitória da Conquista, Vitória da Conquista, Bahia, Brasil \\ (*E-mail: juniorpublio@hotmail.com) \\ http://dx.doi.org/10.19084/RCA17232
}

Recebido/received: 2017.09.07

Recebido em versão revista/received in revised form: 2018.01.22

Aceite/accepted: 2018.02.22

\section{R E S U M O}

O feijão-frade é uma cultura de grande valor nutricional. Possui grande variabilidade genética, ampla capacidade de adaptação e alto potencial produtivo, mas tem o seu potencial genético pouco explorado. O presente trabalho teve como objetivo avaliar os parâmetros genéticos e as correlações entre componentes da produção, arquitetura da planta e início da floração em 20 genótipos de feijão-frade. O trabalho foi realizado em Vitória da Conquista, Bahia, Brasil. O delineamento experimental foi em blocos casualizados, com vinte tratamentos e quatro repetições. Os tratamentos foram compostos por quinze linhas avançadas e cinco cultivares de feijão-frade. Os dados obtidos foram submetidos à análise de homogeneidade, normalidade e variância, para determinação dos parâmetros genéticos e correlações fenotípicas, genotípicas e ambientais. Foram avaliadas as características: início da floração, altura da planta, altura da primeira vagem, número de vagens por planta, peso da vagem, comprimento da vagem, número de grãos por vagem, índice de grãos, peso de 100 grãos e produtividade. Os resultados permitiram concluir que existe variabilidade genética para todas as características, e que o aumento na produtividade de grãos poderá ser obtido através da seleção indireta das características: número de vagens por planta, peso da vagem e número de grãos por vagem.

Palavras-chave: Vigna unguiculata, cultivares, linhas avançadas, variabilidade genética.

\begin{abstract}
A B S T R A C T
Cowpea is a crop of great nutritional value, possessing great genetic variability, ample capacity of adaptation, high productive potential, but its genetic potential has been little explored. The objective of this work was to evaluate genetic parameters and correlations between components of the production, plant architecture and beginning of flowering in 20 genotypes of cowpea. The work was carried out in Vitória da Conquista, Bahia, Brazil. The experimental design was in randomized blocks, with twenty treatments and four replications. The treatments consisted of fifteen advanced lines and five cultivars of cowpea. The obtained data were submitted to analysis of homogeneity, normality and variance, for determination of genetic parameters and phenotypic, genotypic and environmental correlations. Plant height, first pod height, number of pods per plant, pod weight, pod length, number of grains per pod, grain index, 100 grain weight and productivity were evaluated. The results allowed to conclude that genetic variability was observed for all the characteristics and that the increase in grain yield can be obtained through the indirect selection of the number of pods per plant, pod weight and number of grains per pod characteristics.
\end{abstract}

Keywords: Vigna unguiculata, cultivars, advanced lines, genetic variability. 


\section{INTRODUÇÃO}

Originário de África, o feijão-frade (Vigna unguiculata (L.) Walp.) é conhecido por outros nomes que variam de região para região, sendo chamado no Brasil, principalmente, como feijão-caupi. O Brasil é um dos maiores produtores desta leguminosa, com produção superior a 360 mil toneladas na colheita de 2015/2016 (CONAB, 2017). É uma cultura predominante nas regiões Norte e Nordeste do Brasil, onde tem grande importância como fonte geradora de emprego e rendimento (Oliveira et al., 2010), constituindo um dos principais componentes da alimentação humana (Bezerra et al., 2008).

Em comparação com outras culturas, o feijão-frade tem o seu potencial genético pouco explorado, sendo observadas produtividades médias na Região Centro-Oeste, em torno de 750 kg.ha-1, enquanto no Nordeste a média não ultrapassa os 200 kg.ha-1 (CONAB, 2017). A produtividade brasileira não reflete o potencial produtivo desta cultura (Dutra et al., 2012), visto que em condições experimentais já foram alcançadas produtividades acima de $2.000 \mathrm{~kg} \mathrm{ha}^{-1}$ (Teixeira et al., 2010), e há a expectativa de que esse potencial ultrapasse os $6.000 \mathrm{~kg} \mathrm{ha}^{-1}$ (Freire Filho et al., 2005). Cardoso e Ribeiro (2006) destacam, como um dos principais motivos desta baixa produtividade, a utilização de cultivares tradicionais com baixa capacidade produtiva.

As cultivares de feijão-frade respondem de maneira diferente às condições de solo e clima das regiões de produção, dependendo a resposta das suas características genéticas, fisiológicas e morfológicas. A recomendação de cultivares adaptadas às regiões torna-se indispensável para obter melhores resultados e, consequentemente, obter aumentos de produtividade (Santos, 2013). Segundo este autor, a avaliação de novas variedades nas condições edafoclimáticas onde a cultura será implantada e tendo em consideração as técnicas culturais utilizadas, além de necessária é importante para a recomendação ao produtor das cultivares a serem escolhidas.

Características como a arquitetura da planta, a precocidade e a qualidade do grão têm grande importância nos programas de melhoramento, atendendo ao aumento da utilização de irrigação nas áreas de cultivo e à crescente utilização da mecanização. Plantas mais eretas estão mais aptas para a colheita mecânica e, além disso, as vagens não ficam tão próximas do solo reduzindo-se, assim, a possibilidade de ataques de patógenos (Freire Filho et al., 2005).

A estimativa de parâmetros genéticos tem grande importância, em programas de melhoramento, pois permite ao melhorador fazer inferências sobre a variabilidade genética e antever o ganho com a seleção. A correlação entre os caracteres de interesse para a seleção permite ao melhorador conhecer o grau de associação entre caracteres de importância económica, tendo em vista que a seleção sobre determinado caráter altera o comportamento do outro (Correa et al., 2003).

No feijão-frade, características como o comprimento da vagem e o número de grãos por vagem devem ser consideradas no programa de melhoramento, pois quanto maior for a vagem, maior será o número de grãos, influenciando diretamente a produção (Freire Filho et al., 2000).

Perante estas considerações, o objetivo deste trabalho consistiu em estimar parâmetros genéticos e as correlações genéticas de uma coleção de feijão-frade, com base em caracteres de interesse agronómico, e analisar quais são os caracteres que podem ser utilizados na seleção de genótipos superiores.

\section{MATERIAL E MÉTODOS}

O ensaio foi conduzido num campo experimental situado a $850 \mathrm{~m}$ de altitude, com as coordenadas geográficas de $14^{\circ} 51^{\prime}$ de latitude Sul e $40^{\circ} 50^{\prime}$ de longitude Oeste. O clima regional é classificado como tropical de altitude (Cwa), de acordo com Köppen, e, precipitação média anual de $733,9 \mathrm{~mm}$ (Souza et al., 2010). O solo foi classificado como Cambissolo Háplico Distrófico $\mathrm{Tb}$, com classe textural Franco Argilo Arenosa. A análise de fertilidade apresentou os seguintes resultados: $\mathrm{pH}$ $\left(\mathrm{H}_{2} \mathrm{O}\right)=5,7 ; \mathrm{Al}=0,1 \mathrm{Cmolc} / \mathrm{dm}^{3} ; \mathrm{Ca}=3,2 \mathrm{Cmolc} / \mathrm{dm}^{3} ;$ $\mathrm{Mg}=0,9 \mathrm{Cmolc} / \mathrm{dm}^{3} ; \mathrm{K}=0,28 \mathrm{Cmolc} / \mathrm{dm}^{3}$ e $\mathrm{P}=$ $2,0 \mathrm{mg} / \mathrm{dm}^{3}$.

Foram avaliadas 5 (cinco) cultivares e 15 (quinze) linhas avançadas de feijão-frade de porte ereto e semiereto, selecionadas no Ensaio Preliminar de 
Rendimento - EPR, do programa de melhoramento genético da Embrapa Meio-Norte. O delineamento experimental foi em blocos casualizados, com quatro repetições e 20 genótipos. A parcela experimental foi constituída por quatro linhas de cinco metros de comprimento, com espaçamento de $0,5 \mathrm{~m}$ entre linhas. Como área útil da parcela, utilizaram-se as duas linhas centrais.

A preparação do solo foi realizada por meio mecanizado, com uma lavoura, duas gradagens e abertura de sulcos com $0,50 \mathrm{~m}$ de distância. A adubação à sementeira foi feita conforme o resultado da análise de fertilidade do solo e seguindo as recomendações de adubação para o uso de corretivos e fertilizantes em Minas Gerais (5 $5^{\mathrm{a}}$ aproximação) (Chagas et al. 1999). Na adubação, foram aplicadas $30 \mathrm{~kg} \mathrm{ha}^{-1}$ de $\mathrm{N}$, na forma de ureia, $90 \mathrm{~kg} \mathrm{ha}^{-1}$ de $\mathrm{P}_{2} \mathrm{O}_{5}$, na forma de superfosfato simples e $40 \mathrm{~kg} \mathrm{ha}^{-1}$ de $\mathrm{K}_{2} \mathrm{O}$ na forma de cloreto de potássio.

Foram utilizadas 12 sementes por metro linear. Após a sementeira, os sulcos foram cobertos com uma camada de 2 a $3 \mathrm{~cm}$ de solo. Vinte dias após a sementeira, foi feito o desbaste, deixando oito plantas por metro linear, de modo a obter um povoamento de 160 mil plantas por hectare. Após o desbaste, foi realizada a adubação de cobertura com $40 \mathrm{~kg} \mathrm{ha}^{-1}$ de $\mathrm{N}$ na forma de ureia.

Aos 38 dias após a sementeira, foi realizada uma adubação foliar com molibdato de zinco 150 g.ha-1 e efetuado o controle fitossanitário de Diabrotica speciosa (Germar) (Coleoptera: Chrysomelidae), com a aplicação de $150 \mathrm{~mL} \mathrm{ha}^{-1}$ de inseticida piretroide. Aos 40 dias após a sementeira, foi feito o controlo de plantas daninhas através de monda manual. O início da floração foi registrado quando apareceram as primeiras flores abertas na parcela útil. A colheita foi feita quando as parcelas atingiram $70 \%$ de vagens secas, sendo colhidas dez plantas da área útil para as avaliações das características referentes aos componentes da produção, altura da planta, altura da primeira vagem, número de vagens por planta, peso da vagem, comprimento de vagem, número de grãos por vagem, índice de grãos (relação entre o peso dos grãos e o peso da vagem) e peso de 100 grãos.

As vagens restantes da parcela útil foram colhidas e colocadas em estufa agrícola para secagem até atingirem um teor de humidade próximo de $13 \%$. Após a secagem, as sementes foram separadas das palhas, limpas com o auxílio de peneira e pesadas para obtenção da produtividade total da parcela.

Para verificar a existência de variabilidade entre os genótipos, os dados foram submetidos à análise de variância pelo teste $\mathrm{F}$. Utilizou-se o programa de assistência estatística Sisvar (Ferreira, 2011), versão 5.3 .

Os parâmetros genéticos foram determinados a partir das seguintes expressões (Cruz et al., 2004), em que $\mathrm{QMg}$ corresponde ao quadro médio do genótipo e QMr ao quadrado médio do resíduo:

a) Variância Fenotípica: $\mathrm{VP}=\mathrm{QMg} / \mathrm{r}$

b) Variância Genotípica: $\mathrm{VG}=(\mathrm{QMg}-\mathrm{QMr}) / \mathrm{r}$

c) Variância Ambiental: $\mathrm{VE}=\mathrm{QMr} / \mathrm{r}$

d) Heritabilidade: $\mathrm{h} 2=\mathrm{VG} / \mathrm{VP}$

e) Coeficiente de VariaçãoFenotípica: $\mathrm{CV}_{\mathrm{P}}=(\sqrt{\mathrm{VP}} / \overline{\mathrm{X}}) \times 100$

f) Coeficientede VariaçãoGenotípica: $C V_{G}=(\sqrt{V G} / \bar{X}) \times 100$

g) CoeficientedeVariação Ambiental: $\mathrm{CV}_{\mathrm{E}}=(\sqrt{\mathrm{VE}} / \overline{\mathrm{X}}) \times 100$

h) Coeficiente de Variação Relativa (Coeficiente “b”) $=\mathrm{CV}_{\mathrm{G}} / \mathrm{CV}_{\mathrm{E}}$

i) Ganho Genético: GA = i $\Delta p$ h2

$\mathrm{i}=$ Intensidade de Seleção $(5 \%)=2,06$ (Constante)

$\Delta \mathrm{p}=$ Desvio Padrão da Variância Fenotípica: $\sqrt{ } \mathrm{VP}$ h2 $=$ Heritabilidade

j) $\mathrm{GAM}=[(\mathrm{GA} / \overline{\mathrm{X}}) \times 100]$ - Ganho Genético em Percentagem da Média

Tem-se o ganho genético assumindo uma intensidade de seleção de 5\% num ciclo de avaliação.

Para estimar as correlações, foram utilizadas as expressões citadas por Falconer (1987) e Ramalho et al. (1993):

a) Correlação fenotípica (rP)

$r P(X Y)=\frac{\operatorname{COV}_{P(X Y)}}{\sqrt{\sigma^{2} P X \cdot \sigma^{2} P Y}}$

b) Correlação genotípica $(\mathrm{r} G)$

$r G(X Y)=\frac{\operatorname{COV}_{G(X Y)}}{\sqrt{\sigma^{2} G X \cdot \sigma^{2} G Y}}$ 
c) Correlação ambiental (rE)

$$
r E(X Y)=\frac{\operatorname{COV}_{E(X Y)}}{\sqrt{\sigma^{2} E X \cdot \sigma^{2} E Y}}
$$

Em que: $r(X Y)=$ correlação entre os caracteres $X$ e $Y$; $\mathrm{COV}_{(\mathrm{XY})}=$ covariância entre os dois caracteres; ee= variância dos caracteres $X$ e $Y$, respectivamente.

Os parâmetros genéticos e fenotípicos foram estimados através do aplicativo computacional GENES (Cruz, 2006). Aplicou-se o teste de significância de Student $(t)$ nas correlações.

\section{RESULTADOS E DISCUSSÃO}

A análise de variância (Quadro 1) mostra que houve efeito significativo dos genótipos para todas as características observadas, demonstrando a existência de ampla variabilidade genética na coleção estudada, o que é fundamental para a seleção no programa de melhoramento desta espécie.

A análise dos componentes da variância revelou que na composição da variância fenotípica, a variação genética foi superior em relação à variação ambiental, para todas as características estudadas. Este resultado indica maior influência dos fatores genéticos em relação aos componentes ambientais na expressão dos caracteres, o que vai facilitar a seleção da quase totalidade das características estudadas e é evidenciado pela baixa diferença de valores entre $\mathrm{CV}_{\mathrm{P}}$ e $\mathrm{CV}_{\mathrm{G}}$. Resultados semelhantes foram obtidos por Teixeira et al. (2007), Ubi et al. (2001), Andrade et al. (2010), Benvindo et al. (2010), Correa et al. (2012) e Correa et al. (2015).

Quadro 1 - Análise de variância e estimativa de parâmetros genéticos das características: início da floração (IF), altura da planta (AP), altura da primeira vagem (AV), número de vagens por planta (NVP), peso da vagem (PV), comprimento da vagem (CPV), número de grãos por vagem (NGV), índice de grãos (IG), peso de 100 grãos (P100G) e produtividade (PROD) de genótipos de feijão-frade, cultivados em Vitória da Conquista - BA, 2014

\begin{tabular}{|c|c|c|c|c|c|c|c|c|c|c|c|}
\hline \multirow{2}{*}{ FV } & \multirow{2}{*}{ GL } & \multicolumn{10}{|c|}{ Quadrado Médio } \\
\hline & & IF & AP & AV & NVP & PV & $\mathrm{CPV}$ & NGV & IG & P100G & PROD \\
\hline Blocos & 3 & $1.60^{\mathrm{ns}}$ & $91.89^{* *}$ & $17.66^{\mathrm{ns}}$ & $20.08^{*}$ & $0.04^{\mathrm{ns}}$ & $1.57^{\mathrm{ns}}$ & $0.94^{\mathrm{ns}}$ & $14.83^{\text {ns }}$ & $2.32^{\mathrm{ns}}$ & $315198.36^{\text {ns }}$ \\
\hline Tratamentos & 19 & $17.44^{* *}$ & $65.74^{* *}$ & $57.83^{* *}$ & $14.68^{*}$ & $0.40^{* *}$ & $8.91^{* *}$ & $11.54^{* *}$ & $22.60^{* *}$ & $33.29^{* *}$ & $767255.04^{* *}$ \\
\hline Resíduo & 57 & 1.21 & 19.83 & 10.34 & 6.94 & 0.15 & 1.56 & 1.16 & 5.37 & 2.87 & 163384.72 \\
\hline Média & & 63.00 & 41.98 & 14.52 & 9.00 & 2.89 & 17.25 & 10.00 & 78.00 & 22.59 & 1571.16 \\
\hline CV (\%) & & 1.75 & 10.61 & 22.14 & 30.27 & 13.28 & 7.24 & 10.63 & 2.96 & 7.50 & 25.73 \\
\hline \multicolumn{12}{|c|}{ Parâmetros Genéticos } \\
\hline VP & & 4.36 & 16.44 & 14.46 & 3.68 & 0.10 & 2.23 & 2.88 & 5.65 & 8.33 & 191813.76 \\
\hline VG & & 4.06 & 11.48 & 11.87 & 1.94 & 0.06 & 1.84 & 2.59 & 4.31 & 7.61 & 150967.58 \\
\hline VE & & 0.30 & 4.96 & 2.59 & 1.74 & 0.04 & 0.39 & 0.29 & 1.34 & 0.72 & 40846.18 \\
\hline CVP (\%) & & 3.31 & 9.66 & 26.19 & 21.30 & 10.94 & 8.65 & 16.96 & 3.05 & 12.77 & 27.88 \\
\hline CVG (\%) & & 3.20 & 8.07 & 23.73 & 15.48 & 8.65 & 7.86 & 16.08 & 2.66 & 12.21 & 24.73 \\
\hline CVE (\%) & & 0.87 & 5.30 & 11.07 & 14.64 & 6.70 & 3.62 & 5.39 & 1.49 & 3.75 & 12.86 \\
\hline$h^{2}(\%)$ & & 93.09 & 69.84 & 82.12 & 52.79 & 62.50 & 82.49 & 89.91 & 76.24 & 91.38 & 78.71 \\
\hline GA & & 4.00 & 5.83 & 6.43 & 2.08 & 0.41 & 2.54 & 3.14 & 3.73 & 5.43 & 710.09 \\
\hline GAM (\%) & & 6.36 & 13.89 & 44.30 & 23.16 & 14.09 & 14.70 & 31.41 & 4.79 & 24.04 & 45.20 \\
\hline CVG/CVE & & 3.67 & 1.52 & 2.14 & 1.06 & 1.29 & 2.17 & 2.99 & 1.79 & 3.26 & 1.92 \\
\hline
\end{tabular}

Variação fenotípica (VP), variação genotípica (VG), variação ambiental (VE), coeficiente de variação fenotípica (CVP), coeficiente de variação genotípica (CVG), coeficiente de variação ambiental (CVE), heritabilidade $\left(h^{2}\right)$, ganho genético (GA), ganho genético em percentagem da média (GAM).

**Significativo a $1 \%$ pelo teste $F$, *Significativo a $5 \%$ pelo teste $F$, ns Não significativo. 
A estimativa de heritabilidade foi significativamente alta para todas as características, tendo valores superiores a $50 \%$. Tal estimativa é um importante parâmetro genético que desempenha papel significativo na seleção de diferentes genótipos de uma população (Manggoel et al., 2012). De acordo com Manggoel et al. (2012) e Rashwan (2010), altas heritabilidades com baixos ganhos genéticos indicam o predomínio da ação génica não aditiva na expressão da característica, o que foi evidenciado neste estudo para a grande maioria das características. Apenas a produtividade apresentou alta heritabilidade com alto ganho genético, sugerindo o predomínio da ação génica aditiva na expressão desta característica. Este resultado indica que devem ser utilizados métodos simples de seleção para obter ganhos em produtividade.

Foi verificada alta heritabilidade $(93,09 \%)$ para a característica início da floração, em oposição a Correa et al. (2015) que encontraram baixa heritabilidade $(35,93 \%)$ para esta característica.

Os coeficientes de variação genotípica apresentaram valores que variaram de $2,66 \%$ para o índice de grãos (IG) a 24,73\% para a produtividade (PROD). Valores de produtividade $(23,90 \%)$ análogos a este também foram observados por Lopes et al. (2001). O coeficiente de variação ambiental variou entre o valor mínimo de $0,87 \%$ no o início da floração (IF) e o valor máximo de $14,64 \%$ para o número de vagens por planta (NVP). Todos os valores foram inferiores a $20 \%$, demonstrando a baixa suscetibilidade dos genótipos aos efeitos do ambiente.

O ganho genético em percentagem da média apresentou valores altos, de acordo com a classificação proposta por Johnson et al. (1955), com valores superiores a $20 \%$ para as características altura da primeira vagem $(\mathrm{AV})$, número de vagens por planta (NVP), peso de 100 grãos (P100G) e produtividade (PROD), tendo a produtividade apresentado um ganho superior a $45 \%$. As características início da floração (IF) e índice de grãos (IG) apresentaram valores inferiores a 10\% de ganho genético.

Os coeficientes de Variação Relativa $\left(\mathrm{CV}_{\mathrm{G}} / \mathrm{CV}_{\mathrm{E}}\right)$ apresentaram resultados superiores a 1 para todas as características analisadas, indicando que é favorável a seleção pois a variação ambiental é menor que a variação genética em relação à média. Este resultado indica que estas características devem ser utilizadas na seleção de plantas pelos programas de melhoramento genético.

No Quadro 2 são apresentados os resultados das estimativas das correlações fenotípicas $(r P)$, genotípicas $(r G)$ e ambientais $(r E)$, entre as características avaliadas. Em geral, observa-se concordância dos sinais entre as correlações fenotípicas e genotípicas, o que indica precisão na amostragem e/ou na estimativa dos parâmetros avaliados (Falconer, 1981). Observa-se, ainda, que as correlações genotípicas, na grande maioria, apresentam valores superiores às suas correspondentes correlações ambientais e fenotípicas, resultados também observados por Correa et al. (2012) e Silva e Neves (2011).

A produtividade (PROD) apresentou correlação genotípica e fenotípica negativa para as características altura da planta (AP) e altura da primeira vagem (AV). Foi observada correlação ambiental $(r E)$ e correlação genotípica $(r G)$ positiva elevada entre as características número de grãos por vagem (NVP) $x$ produtividade (PROD), peso da vagem $(\mathrm{PV}) \times$ produtividade (PROD) e número de grãos por vagem (NGV) x produtividade (PROD). Este resultado evidencia que os componentes de produção número de grãos por vagem (NVP), peso da vagem $(\mathrm{PV})$ e número de grãos por vagem (NGV) são os que mais contribuem para a produtividadedo feijão-frade, superando o peso de 100 grãos (P100G). Neste estudo, o peso de 100 grãos (P100G) não apresentou correlação significativa com a produtividade (PROD). Resultados semelhantes também foram observados por Mohammed et al. (2009) e Silva et al. (2014). De acordo Stoilova e Pereira (2013), os componentes que mais contribuem para a produção são o número de vagens por planta e o número de sementes por vagens.

Características com alta magnitude de correlação (fenotípica e genotípica) podem ser consideradas nas estratégias de melhoramento por seleção indireta, enquanto que características com baixa magnitude de correlação (fenotípica e genotípica) podem ser consideradas nas estratégias de melhoramento por seleção direta (Cruz et al., 2004).

O início da floração apresentou correlação fenotípica e genotípica $(r P$ e $r G)$ positiva para as característicasaltura da planta (AP) e altura da primeira 
Quadro 2 - Estimativas de correlações fenotípicas, genotípicas e ambientais ( $r P$, rG e rE, respectivamente) entre as características início da floração (IF), altura da planta (AP), altura da primeira vagem (AV), número de vagens por planta (NVP), peso da vagem (PV), comprimento da vagem (CPV), número de grãos por vagem (NGV), índice de grãos (IG), peso de 100 grãos (P100G) e produtividade (PROD) de genótipos de feijão-frade, cultivados em Vitória da Conquista - BA, 2014

\begin{tabular}{|c|c|c|c|c|c|c|c|c|c|c|}
\hline Variáveis & & $\mathrm{AP}$ & $\mathrm{AV}$ & NVP & PV & CPV & NGV & IG & P100G & PROD \\
\hline \multirow{3}{*}{ IF } & $\mathrm{rP}$ & $0,5326^{*}$ & $0,5149^{*}$ & $-0,1298^{\mathrm{ns}}$ & $-0,0827^{\mathrm{ns}}$ & $0,0208^{\text {ns }}$ & $0,3255^{\mathrm{ns}}$ & $-0,2875^{\mathrm{ns}}$ & $-0,2803^{\mathrm{ns}}$ & $0,0581^{\mathrm{ns}}$ \\
\hline & $\mathrm{rG}$ & $0,6654^{* *}$ & $0,5908^{* *}$ & $-0,2111^{\mathrm{ns}}$ & $-0,1870^{\mathrm{ns}}$ & $-0,0181^{\mathrm{ns}}$ & $0,3327^{\mathrm{ns}}$ & $-0,3554^{\mathrm{ns}}$ & $-0,3053^{\text {ns }}$ & $0,0812^{\mathrm{ns}}$ \\
\hline & $\mathrm{rE}$ & $-0,0128^{\mathrm{ns}}$ & $0,0020^{\mathrm{ns}}$ & $0,0926^{\mathrm{ns}}$ & $0,3559^{\text {ns }}$ & $0,3171^{\mathrm{ns}}$ & $0,2547^{\mathrm{ns}}$ & $0,0805^{\mathrm{ns}}$ & $-0,0254^{\mathrm{ns}}$ & $-0,0877^{\mathrm{ns}}$ \\
\hline \multirow{3}{*}{$\mathrm{AP}$} & $\mathrm{rP}$ & & $0,8293^{* *}$ & $-0,3714^{\mathrm{ns}}$ & $-0,3948^{\mathrm{ns}}$ & $0,1322^{\mathrm{ns}}$ & $-0,1090^{\mathrm{ns}}$ & $-0,3491^{\mathrm{ns}}$ & $-0,0258^{\mathrm{ns}}$ & $-0,3696^{\mathrm{ns}}$ \\
\hline & $\mathrm{rG}$ & & $0,9098^{* *}$ & $-0,8939^{* *}$ & $-0,5979^{* *}$ & $0,1660^{\mathrm{ns}}$ & $-0,2105^{\text {ns }}$ & $-0,5500^{*}$ & $-0,0537 \mathrm{~ns}$ & $-0,7025^{* *}$ \\
\hline & $\mathrm{rE}$ & & $0,6041^{* *}$ & $0,4531^{*}$ & $0,0044^{\mathrm{ns}}$ & $0,0270^{\mathrm{ns}}$ & $0,3314^{\mathrm{ns}}$ & $0,1955^{\mathrm{ns}}$ & $0,0950^{\mathrm{ns}}$ & $0,5970^{* *}$ \\
\hline \multirow{3}{*}{$\mathrm{AV}$} & $\mathrm{rP}$ & & & $-0,6187^{* *}$ & $-0,2118^{\mathrm{ns}}$ & $0,0879^{n s}$ & $-0,0277^{\mathrm{ns}}$ & $-0,1976^{\text {ns }}$ & $-0,1655^{\mathrm{ns}}$ & $-0,4564^{*}$ \\
\hline & $\mathrm{rG}$ & & & $-0,9389^{* *}$ & $-0,2928^{\mathrm{ns}}$ & $0,1099 \mathrm{~ns}$ & $-0,0490^{\mathrm{ns}}$ & $-0,2569^{\mathrm{ns}}$ & $-0,2273^{\text {ns }}$ & $-0,6567^{* *}$ \\
\hline & $\mathrm{rE}$ & & & $-0,0034^{\mathrm{ns}}$ & $-0,0052^{\mathrm{ns}}$ & $-0,0145^{\mathrm{ns}}$ & $0,1076^{\text {ns }}$ & $0,0274^{\mathrm{ns}}$ & $0,2192^{\mathrm{ns}}$ & $0,3664^{\mathrm{ns}}$ \\
\hline \multirow{3}{*}{ NVP } & $\mathrm{rP}$ & & & & $0,0106^{\text {ns }}$ & $0,0403^{\text {ns }}$ & $0,1934^{\mathrm{ns}}$ & $-0,0218^{\mathrm{ns}}$ & $0,3085^{\mathrm{ns}}$ & $0,6517^{* *}$ \\
\hline & $\mathrm{rG}$ & & & & $-0,0116^{\mathrm{ns}}$ & $-0,0082^{\mathrm{ns}}$ & $0,1637^{\mathrm{ns}}$ & $-0,1164^{\mathrm{ns}}$ & $0,4053^{\mathrm{ns}}$ & $0,7332^{* *}$ \\
\hline & $\mathrm{rE}$ & & & & $0,0414^{\mathrm{ns}}$ & $0,1590^{\mathrm{ns}}$ & $0,3696^{\mathrm{ns}}$ & $0,1552^{\mathrm{ns}}$ & $0,1351^{\mathrm{ns}}$ & $0,5653^{* *}$ \\
\hline \multirow{3}{*}{ PV } & $\mathrm{rP}$ & & & & & $0,5250^{*}$ & $0,7301^{* *}$ & $0,4692^{*}$ & $-0,0913^{\text {ns }}$ & $0,5028^{*}$ \\
\hline & $\mathrm{rG}$ & & & & & $0,4523^{*}$ & $0,7732^{* *}$ & $0,6471^{* *}$ & $-0,1720^{\mathrm{ns}}$ & $0,6966^{* *}$ \\
\hline & $\mathrm{rE}$ & & & & & $0,7814^{* *}$ & $0,7683^{* *}$ & $0,0711^{\mathrm{ns}}$ & $0,1941^{\mathrm{ns}}$ & $0,0452^{\mathrm{ns}}$ \\
\hline \multirow{3}{*}{$\mathrm{CPV}$} & $\mathrm{rP}$ & & & & & & $0,7440^{* *}$ & $0,4802^{*}$ & $-0,2383^{n s}$ & $0,2296^{\mathrm{ns}}$ \\
\hline & $\mathrm{rG}$ & & & & & & $0,7455^{* *}$ & $0,5810^{* *}$ & $-0,3031^{\mathrm{ns}}$ & $0,2621^{\mathrm{ns}}$ \\
\hline & $\mathrm{rE}$ & & & & & & $0,7675^{* *}$ & $0,0951^{\mathrm{ns}}$ & $0,1681^{\mathrm{ns}}$ & $0,0951^{\mathrm{ns}}$ \\
\hline \multirow{3}{*}{ NGV } & $\mathrm{rP}$ & & & & & & & $0,4382^{\mathrm{ns}}$ & $-0,2149^{\mathrm{ns}}$ & $0,5364^{*}$ \\
\hline & $\mathrm{rG}$ & & & & & & & $0,4657^{*}$ & $-0,2541^{\mathrm{ns}}$ & $0,5961^{* *}$ \\
\hline & $\mathrm{rE}$ & & & & & & & $0,3394^{\mathrm{ns}}$ & $0,1312^{\mathrm{ns}}$ & $0,2384^{\mathrm{ns}}$ \\
\hline \multirow{3}{*}{ IG } & $\mathrm{rP}$ & & & & & & & & $0,0194^{\mathrm{ns}}$ & $0,1871^{\mathrm{ns}}$ \\
\hline & $\mathrm{rG}$ & & & & & & & & $0,0675^{\mathrm{ns}}$ & $0,2346^{\mathrm{ns}}$ \\
\hline & $\mathrm{rE}$ & & & & & & & & $-0,2334^{\mathrm{ns}}$ & $0,0239^{n s}$ \\
\hline \multirow{3}{*}{ P100G } & $\mathrm{rP}$ & & & & & & & & & $0,3246^{\mathrm{ns}}$ \\
\hline & $\mathrm{rG}$ & & & & & & & & & $0,3411^{\mathrm{ns}}$ \\
\hline & $\mathrm{rE}$ & & & & & & & & & $0,2566^{\mathrm{ns}}$ \\
\hline
\end{tabular}

**Significativo a $1 \%$ pelo teste $t$, *Significativo a $5 \%$ pelo teste $t$, ns Não significativo.

vagem (AV), indicando que os genótipos com floração mais tardia apresentam maior duração da fase vegetativa e, consequentemente, plantas mais altas e maior altura para a inserção da primeira vagem. Resultados semelhantes foram observados por Matos Filho et al. (2009) para os parâmetros número de dias até a floração e comprimento do ramo principal.
A altura de inserção da vagem é uma característica importante no melhoramento do feijão-frade, devido à tendência de mecanização em todas as fases do cultivo. Silva (2008) ressalta que, para uma colheita mecanizada com baixa percentagem de perda de grãos, são necessárias plantas de feijão-frade com porte ereto e vagens no terço superior da planta. De acordo com Kappes et al. (2008), plantas 
com vagens mais próximas da superfície do solo são mais vulneráveis ao ataque de doenças fúngicas.

Observou-se uma correlação fenotípica $(r P)$, genotípica $(r G)$ e ambiental $(r E)$ positiva forte entre o comprimento da vagem (CPV) e o número de grãos por vagem (NGV), permitindo inferir que a seleção para o aumento do comprimento das vagens leva ao aumento do número de sementes por vagem e, consequentemente, a um aumento da produção. Resultados semelhantes também foram observados por Andrade et al. (2010) e Correa et al. (2012).

O índice de grãos apresentou correlação genotípica positiva para as características peso da vagem, comprimento da vagem e número de grãos por vagem, resultados já esperados, visto que o índice de grãos é a relação entre o peso dos grãos e o peso das vagens.

De acordo com Cruz (2005), a seleção baseada em vários caracteres tem apresentado superioridade em relação a outros métodos. Para Cruz e Regazzi (1997), a seleção baseada num só caráter não é um critério adequado para representar o bom desempenho econômico de uma planta, uma vez que a seleção baseada no mesmo pode conduzir ao desenvolvimento de tipos economicamente insatisfatórios.

\section{CONCLUSÕES}

Os genótipos avaliados apresentam potencial para a seleção e obtenção de ganhos genéticos adicionais para todas as características estudadas.

O aumento da produtividade pode ser obtido por meio da seleção indireta das características número de vagens por planta, peso da vagem e número de grãos por vagem.

A altura da vagem é uma característica que deve ser incluída nos critérios de seleção dos programas de melhoramento. No entanto, esse parâmetro pode influenciar de maneira indireta e negativa a produtividade, pelo que se sugere uma seleção baseada em índices.

\section{AGRADECIMENTOS}

Ao professor, pesquisador, Dr. Otoniel M. Morais (In Memorian), à Embrapa Meio-Norte e à Universidade Estadual do Sudoeste da Bahia pelo auxílio na implantação e na condução do trabalho experimental.

\section{REFERÊNCIAS BIBLIOGRÁFICAS}

Andrade, F.N.; Rocha, M.N.; Gomes, R.L.F.; Freire Filho, F.R. \& Ramos, S.R. (2010) - Estimativas de parâmetros genéticos em genótipos de feijão-caupi avaliados para feijão fresco. Revista Ciência Agronômica, vol. 41, n. 2, p. 253-258.

Benvindo, R.N.; Silva, J.A.L.; Freire Filho, F.R.; Almeida, A.L.G.; Oliveira, J.T.S. \& Bezerra, A.A.C. (2010) - Avaliação de genótipos de feijão caupi semi-prostrado em cultivo de sequeiro e irrigado. Comunicata Scientie, vol. 1, p. 23-28.

Bezerra, A.A.C.; Távora, F.J.A.F.; Freire Filho, F.R. \& Ribeiro V.Q. (2008) - Morfologia e produção de grãos em linhagens modernas de feijão-caupi submetidas a diferentes densidades populacionais. Revista de Biologia e Ciências da Terra, vol. 8, n. 1, p. 85-92.

Cardoso, M.J. \& Ribeiro V.Q. (2006) - Desempenho agronômico do feijão-caupi, cv. Rouxinol, em função de espaçamentos entre linhas e densidades de plantas sob regime de sequeiro. Revista Ciência Agronômica, vol. 37, n. 1, p. 102-105.

Chagas, J.M.; Braga, J.M.; Vieira, C.; Salgado, L.T.; Junqueira Neto, A.; Araújo, G.A.A.; Andrade, M.J.B.; Lana, R.M.Q. \& Ribeiro, A.C. (1999) - Feijão. In: Ribeiro, A.C.; Guimarães, P.T.G. \& Alvarez, V.V.H. (Eds.) - Recomendação para o uso de corretivos e fertilizantes em Minas Gerais, 5a aproximação. Viçosa: Comissão de Fertilidade do Solo do Estado de Minas Gerais. p. 306-307.

CONAB (2017) - Acompanhamento da Safra Brasileira de Grãos: Quinto levantamento. Companhia Nacional de Abastecimento. [cit. 2017-03-04]. http://www.conab.gov.br/OlalaCMS/uploads/arquivos/17_02_16_11_51_51_boletim_ graos_fevereiro_2017.pdf 
Correa, A.M.; Ceccon, G.; Correa, C.M.A. \& Delben, D.S. (2012) - Estimativas de parâmetros genéticos e correlações entre caracteres fenológicos e morfoagronômicos em feijão-caupi. Revista Ceres, vol. 59, n. 1, p. 88-94. http://dx.doi.org/10.1590/S0034-737X2012000100013

Correa, A.M.; Braga, D.C.; Ceccon, G.; Oliveira, L.V.A. de; Lima, A.R. de S. \& Teodoro, P.E. (2015) Variabilidade genética e correlações entre caracteres de feijão-caupi. RevistaAgro@mbiente On-line, vol. 9, n. 1, p. 42-47. http://dx.doi.org/10.18227/1982-8470ragro.v9i1.2252

Correa, A.M.; Gonçalves, M.C.; Destro, D.; Souza, L.C.F. \& Sobrinho, T.A. (2003) - Estimates of genetics parameters in common bean genotypes. Crop Breeding and Applied Biotechonology, vol. 3, n. 3, p. 223-230.

Cruz, C.D. (2005) - Princípios de genética quantitativa. Viçosa, UFV, 394 p.

Cruz, C.D. (2006) - Programa GENES: Biometria.Viçosa, UFV, 382 p.

Cruz, C.D. \& Regazzi, A.J (1997) - Modelos biométricos aplicados ao melhoramento genético. Viçosa, UFV, 130 p.

Cruz, C.D.; Regazzi, A.J. \& Carneiro, P.C.S. (2004) - Modelos biométricos aplicados ao melhoramento genético, $3^{\text {a }}$ ed. Viçosa, $480 \mathrm{p}$.

Dutra, A.S.; Bezerra, F.T.C.; Nascimento, P.R.; \& Lima, D.C. (2012) - Produtividade e qualidade fisiológica de sementes de feijão caupi em função da adubação nitrogenada. Revista Ciência Agronômica, vol. 43, n. 4, p. 816-821.

Falconer, D.S. (1981) - Introdução à Genética Quantitativa. Viçosa, MG: UFV, 279 p.

Falconer, D.S. (1987) - Introdução a genética quantitativa. Viçosa: editora UFV, 279p.

Ferreira, D.F. (2011) - Sisvar: a computer statistical analysis system. Ciência e Agrotecnologia, vol. 35, n. 6, p. 1039-1042. http://dx.doi.org/10.1590/S1413-70542011000600001

Freire Filho, F.R.; Ribeiro, V.Q. \& Santos, A.A. (2000) - Cultivares de caupi para a região Meio-Norte do Brasil. In: Cardoso, M. J. (Org.) - A cultura do feijão caupi no Meio-Norte do Brasil. Teresina: Embrapa MeioNorte, (Embrapa Meio-Norte. Circular Técnica, 28), 264p.

Freire Filho, F.R.; Ribeiro, V.Q.; Barreto, P.D. \& Santos, A.A. (2005) - Melhoramento Genético. In: Freire Filho, F.R.; Lima, J.A.A. \& Ribeiro, V.Q. (Eds.) - Feijão-caupi: avanços tecnológicos. Embrapa Informação Tecnológica. p. 29-92.

Johnson, H.W.; Robinson, H.F. \& Comstock, R.I. (1955) - Estimates of genetic and environmental variability in soybeans. Agronomy Journal, vol. 47, p. 314-318.

Kappes, C.; Wruck, F.C.; Carvalho, M.A.C de \& Yamashita, O.M. (2008) - Feijão comum: características morfo-agronômicas de cultivares. In: Anais Congresso Nacional De Pesquisa de Feijão, 9, Campinas, Brasil IAC, p. 506-509.

Lopes, A.C.; Freire Filho, F.R.; Silva, R.Q.B.; Campos, F.L. \& Rocha, M.M. (2001) - Variabilidade e correlações entre caracteres agronômicos em caupi (Vigna unguiculata). Pesquisa Agropecuária Brasileira, vol. 36, n. 3, p. 515-529. http://dx.doi.org/10.1590/S0100-204X2001000300016

Manggoel, W.; Uguru, M.I.; Ndam, O.N. \& Dasbak, M.A. (2012) - Genetic variability, correlation and path coefficient analysis of some yield components of ten cowpea (Vigna unguiculata (L.) Walp) accessions. Journal of Plant Breeding and Crop Science, vol. 4, n. 5, p. 80-86.

Matos Filho, C.H.A.; Gomes, R.L.F.; Rocha, M.M.; Freire Filho, F.R.\& Lopes, A.C.A. (2009) - Potencial de Produtivos de progênies de feijão-caupi com arquitetura ereta de planta. Ciência Rural, vol. 39, n. 2, p. 348-345. http://dx.doi.org/10.1590/S0103-84782009000200006

Mohammed, M.S.; Russom, Z.E. \& Abdul, S.D. (2009) - Inheritance of hairiness and pod shattering, heritability and correlation studies in crosses between cultivated cowpea (Vigna unguiculata (L.) Walp.) and its wild (var. pubescens) relative. Euphytica, vol. 171, n. 3, p. 397-407. http://.dx.doi.org/10.1007/s10681-009-0058-6

Oliveira, O.M.S.; Silva, J.F.; Gonçalves, J.R.P. \& Klehm, C.S. (2010) - Período de convivência das plantas daninhas com cultivares de feijão-caupi em várzea no amazonas. Planta Daninha, vol. 28, n. 3, p. 523-530. http://dx.doi.org/10.1590/S0100-83582010000300009

Ramalho, M.A.P.; Santos, J.B. \& Zimmermann, M.J.O. (1993) - Genética quantitativa em plantas autógamas: aplicações ao melhoramento do feijão. Goiânia, UFG, 271 p.

Rashwan, A. (2010) - Estimates of some genetic parameters using six populations of two cowpea hybrids. Asian Journal of Crop Science, vol. 2, n. 4, p. 261-266. http://dx.doi.org/10.3923/ajcs.2010.261.267 
Santos, F. (2013) - Produtividade de cultivares de feijão-caupi no Agreste Paraibano. Tecnologia e Ciência Agropecuária, vol. 7 n. 4, p. 31-36.

Silva, J.G. da (2008) - Altura de corte das plantas e perda de feijão com colhedora automotriz axial. In: Congresso Nacional de Pesquisa De Feijão, 9, Campinas, Brasil, IAC.

Silva, J.A.L.D. \& Neves, J.A. (2011) - Componentes de produção e suas correlações em genótipos de feijãocaupi em cultivo de sequeiro e irrigado. Revista Ciência Agronômica, vol. 42, n. 3, p. 702-713.

Silva, A.C.; Morais, O.M.; Santos, J.L.; D'Arede, L.O.; Silva, C.J. \& Rocha, M.M. (2014) - Estimativa de parâmetros genéticos em Vigna unguiculata. Revista de Ciências Agrárias, vol. 37, n. 4, p. 399-407.

Souza, M.J.L.; Viana, A.E.S.; Matsumoto, S.N.; Vasconcelos, R.C.; Sediyama, T. \& Morais, O.M. (2010) Características agronômicas da mandioca relacionadas à interação entre irrigação, épocas de colheita e Cloreto de Mepiquat. Acta Scientiarum Agronomy, vol. 32, n. 1, p. 45-53. http://dx.doi.org/10.4025/actasciagron. v32i1.720

Stoilova, T. \& Pereira, G. (2013) -Assessment of the genetic diversity in a germplasm collection of cowpea (Vigna unguiculata (L.) Walp.) using morphological traits. African Journal of Agricultural Research, vol. 8, n. 2, p. 208-215.

Teixeira, I.R.; Silva, G.C.; Oliveira, J.P.R.; Silva, A.G.\& Pelá, A. (2010) - Desempenho agronômico e qualidade de sementes de cultivares de feijão-caupi naregião do cerrado. Revista Ciência Agronômica, vol. 41, n. 2, p. 300-307.

Teixeira, N.J.P.; Machado, C.F.; Freire Filho, F.R.; Rocha, M.M. \& Gomes, R.L.F. (2007) - Produção, componentes de produção e suas interrelações em genótipos de feijão-caupi [Vigna unguiculata (L.) Walp.] de porte ereto. Revista Ceres, vol. 54, n. 314, p. 374-382.

Ubi, B.E.; Mignouna, H. \& Obigbesan, G. (2001) - Segregation of seed weight, pod length and days to flowering. African Journal of Crop Science, vol. 9, p. 463-470. 